\title{
Avaliação de sistema e políticas educacionais: uma análise dos resultados do SAEB do Paraná
}

Educational system and educational policies assessment: an analysis of the results of SAEB/Paraná

\section{Ednéla Consolin Poli¹}

\section{Resumo:}

Este artigo tem por objetivo apresentar uma discussão dos resultados do Sistema de Avaliação da Educação Básica - Saeb no período de 1995/2005 do Estado do Paraná. Estes resultados serão discutidos, considerando as características sócio-econômicas que refletem nas condições de oferta e qualidade do ensino público do Paraná. Argumenta-se que essa política de avaliação foi gerada como parte de uma política de regulação no contexto do Estado Avaliador. 0 objetivo principal desta pesquisa está centrado na análise das relações determinantes entre política educacional e resultados da avaliação de sistema. Finalmente, propomos questões para a reflexão sobre os resultados do Saeb e as políticas públicas de educação.

Palavras-chave: Avaliação de Sistema. Política Educacional. Saeb.

\begin{abstract}
:
This article aims to present a discussion on the results of the Elementary Education Assessment System - Saeb in the period of 1995/2005 in the State of Paraná, Brazil. These results will be discussed considering the socio-economic characteristics which reflect on the conditions of the supply and quality of public education in Paraná. It is said that this assessment policy was generated as part of a regulatory policy in the context of the State Evaluator. The main objective of this research is focused on the analysis of the determinant relations between educational policy and the results of the assessment system. Finally, we suggest topics for reflection about the results of the Saeb and the public educational policy.
\end{abstract}

Keywords: Assessment System. Educational Policy. Saeb. 


\section{Introdução}

Este artigo tem por objetivo apresentar uma discussão dos resultados das avaliações do Sistema de Avaliação da Educação Básica - Saeb no período de 1995/2005 do Estado do Paraná, sendo uma das prioridades nas políticas públicas no Brasil na última década. Estes resultados serão discutidos, considerando as características sócio-econômicas que refletem nas condições de oferta e qualidade do ensino público do Paraná. Argumenta-se que essa política de avaliação foi gerada como parte de uma política de regulação no contexto do Estado Avaliador. O objetivo principal desta pesquisa está centrado na análise das relações determinantes entre política educacional e resultados da avaliação de sistema. Finalmente, propomos questões para a reflexão sobre os resultados do Saeb e as políticas públicas de educação.

Os resultados apresentados neste artigo relacionam-se ao processo acerca da pesquisa: "Políticas Educacionais e Qualidade de Ensino: as relações entre o investimento financeiro em educação, as condições de qualidade, o perfil da demanda educacional e o desempenho estudantil em Londrina e Região Metropolitana", desenvolvidos durante o ano de 2008/2009. A pesquisa está cadastrada na Universidade Estadual de Londrina (UEL) e compõe com o Núcleo de Política, Gestão e Financiamento da Educação/Universidade Federal do Paraná (NUPE/UFPR) financiada pelo Observatório de Educação da CAPES/MEC.

A década de 90, que se pode chamar no Brasil de "década da cultura da avaliação", surge no cenário educacional com uma preocupação crescente com respeito à educação. Os profissionais da educação procuram, também por meio da avaliação, entender os rumos que tomou a educação ao se pretender democratizar os espaços da escola com a universalização do ensino fundamental. Procuram-se, por meio das avaliações, informações de eficiência e eficácia das escolas e das políticas públicas implementadas na década em questão. O olhar que se estende para esta questão da avaliação não deve ser um olhar "ingênuo" de causa e efeito ou de responsabilização dos alunos, professores e escolas pelo baixo rendimento escolar.

Palavras de ordem que marcaram governos neoliberais nesta década foram: busca de eficácia na educação, eqüidade e eficiência. Discutindo a lógica da avaliação que marcou esta época, Freitas (2003, p. 17) faz uma análise dos resultados de avaliações realizadas até então e que colocam a escola como o lugar de ensinar tudo a todos, conseguindo-se, assim, a tão propalada eqüidade, como se isso fosse possível nesta estrutura capitalista de sociedade na qual vivemos. É o que ele expõe:

Em resumo, para os que olham para a eficácia da escola na perspectiva ingênua da eqüidade, 0 que resta a fazer é estudar e divulgar quais fatores intrínsecos à escola (recursos pedagógicos e escolares, tamanho da escola, estilo de gestão, treinamento do professor etc.) afetam 0 aumento da qualidade da aprendizagem (proficiência do aluno), apesar das influências do nível socioeconômico sobre o qual, dizem, nada se pode fazer. Este é o sonho liberal: independente do nível socioeconômico (ou, como se diz, descontados os efeitos do nível socioeconômico) todos os alunos deveriam aprender em um nível de domínio elevado. Os socialistas não discordarão do fato de que a escola deva ensinar todos os alunos em um nível elevado de domínio, mas atacarão o problema por outro ângulo - pela necessidade da eliminação dos desníveis socioeconômicos e da distribuição do capital cultural e social, o que supõe discutir como se acumulam outras formas de capital (o econômico, por exemplo).

Pensar um modo refletido e crítico de ler e intervir na realidade social, assim como se apresenta na educação brasileira, tem sido tarefa também de educadores, preocupados com o processo avaliativo enquanto bem social. As avaliações nas escolas tem enfrentado questões internas que são inerentes à sociedade na qual vivemos. Os resultados das avaliações são um bem social do qual nem sempre a escola se apropria.

O desafio para educadores e público em geral é a leitura e interpretação dessas avaliações, quer pontuais, quer de processo, quer em larga escala. O processo avaliativo não termina com a entrega dos resultados; a avaliação continua no momento em que se interpretam os resultados e/ou as aprendizagens adquiridas e a própria ação cognitiva do sujeito que aprende. Como a 
avaliação pode possibilitar uma compreensão da realidade escolar, ela tem possibilitado a tomada de decisões para organizar ou repensar ações locais, regionais ou nacionais em face dos problemas educacionais. Sendo assim, a avaliação precisa estar inserida numa perspectiva política que suscite questionamentos sobre o papel que está assumindo na interpretação dos interesses e contradições sociais.

A reflexão constante, a partir de diferentes perspectivas da avaliação, permite afirmar que a avaliação não é a aplicação de técnicas sofisticadas para conseguir informações sobre a realidade educacional e sim momentos permanentes que conduzem à reflexão do problema educacional brasileiro.

Trata-se, neste texto, das discussões e análises das avaliações de rendimento escolar em larga escala e/ou de grandes grupos, realizadas por meio de ações de políticas públicas ou de programas internacionais, e não de avaliações de aprendizagens realizadas pelos professores em sala de aula.

Conforme argumenta Freitas (1995, p. 230), discutindo a relação escola e sociedade:

$\mathrm{Na}$ escola capitalista, os alunos encontram-se expropriados do processo do trabalho pedagógico e 0 produto do trabalho não chega a ser apropriado por boa parte dos mesmos, e ainda que, em alguns casos, fique em seu poder, carece de sentido para eles. 0 aluno é alienado do processo e como tal é alienado do significado de seu trabalho, do significado do conhecimento que produz - quando produz.

O conhecimento, por ser um bem posto na sociedade, pode levar a uma visão ingênua, "só não aprende quem não quer". A relação entre escola e sociedade culpa, dessa forma, os alunos pela não-apropriação do conhecimento, quando o problema reside não no conhecimento, mas em como fazer com que o conhecimento seja democratizado para todas as classes sociais. A educação como um dos fatores da transformação social e mobilizadores de ações, na busca de uma cidadania efetiva e de direito, tem sido questionada, analisada e colocada sob a ótica de responsabilidade civil diante das dificuldades econômicas, culturais e sociais, segundo Bishop (1988), Mora (2002), D’Ambrosio (1994).
A escola reflete a realidade na qual está inserida, se mudarem os objetivos e os propósitos de uma sociedade, certamente ela também mudará. Cada crise da sociedade pede novos rumos, novas abordagens, nova maneira de viver, de trabalhar, de pensar e re-pensar também a escola. A avaliação não deve ser encarada como uma operação essencialmente teórica na busca de resultados de consenso para informações por meio de índices estatísticos. Ela deve prover a sociedade de informações úteis nos seus mais variados segmentos, sejam eles alunos, pais, professores ou sistemas educacionais.

O desafio para educadores e público em geral é a leitura e interpretação dessas avaliações, quer pontuais, quer de processo, quer em larga escala. O processo avaliativo não termina com a entrega dos resultados; a avaliação continua no momento em que se interpretam os resultados e/ou as aprendizagens adquiridas e a própria ação cognitiva do sujeito que aprende. Como a avaliação pode possibilitar uma compreensão da realidade escolar, ela tem possibilitado a tomada de decisões para organizar ou repensar ações locais, regionais ou nacionais em face dos problemas educacionais. Sendo assim, a avaliação precisa estar inserida numa perspectiva política que suscite questionamentos sobre o papel que está assumindo na interpretação dos interesses e contradições sociais.

O Brasil participou do PISA (Program of International Student Assessment) (ORGANIZACIÓN..., 2000), esse é um programa de avaliação comparada, que procura criar indicadores que apontem a efetividade do sistema de educação. O PISA ocorre a cada três anos e avalia estudantes de 40 países, os testes em sua maioria são da disciplina de matemática e o restante de português (leitura) e ciências.

O resultado foi analisado estudando-se seis níveis e informando-se que quanto maior a porcentagem dos jovens no nível 6, melhor a posição do País no ranking. A classificação dos jovens de 15 anos que fizeram a prova, integrantes dos países membros e convidados da organização, indicou que, no Brasil, metade dos estudantes ficou abaixo do nível 1 e menos de $2 \%$ chegou ao nível 4 . 
Na segunda edição do programa, em 2003, o Brasil apresentou uma melhoria no desempenho nas áreas de matemática e ciências, enquanto em leitura manteve o mesmo nível. Nos resultados de matemática o Brasil passou de 263 para 333 pontos. Os alunos brasileiros, juntamente com outros países não conseguiram atingir o nível 2 .

A última edição do programa foi em 2006, em que o enfoque foi o ensino de ciências. De acordo comos resultados o Brasil melhora seu desempenho na matemática de acordo com os resultados de 2003. Porém fica entre os países que tiveram os piores desempenhos; de 57 países participantes o Brasil conseguiu atingir a $52^{\circ}$ colocação. Os alunos brasileiros tiveram o desempenho menor do que os alunos mais pobres dos países desenvolvidos.

A Universidade de Exeter (Inglaterra), por meio do Centre for Innovation in Mathematics Teaching (CIMT), propôs a diferentes países a participaçãono Kassel Project, em 1994, e do International Project on Mathematical Attainment (IPMA), em 1999. No Brasil, o lócus destes projetos foi a Universidade Estadual de Londrina (PR) - Departamento de Educação, em parceria com a Fundação Ford e coordenado por esta pesquisadora.

O Projeto Kassel, teve seu resultado publicado em Poli e Batista (2001, p. 119-130) e Poli (2004a, p. 41-44). O relatório do Projeto Internacional de Aquisição Matemática está publicado em Poli (2004b, p. 27-56), e o relatório de todos os países participantes, em Burghes; Kaur; Thompson (2004).

Nacionalmente temos o Sistema Nacional de Avaliação da Educação Básica (Saeb), que, ao longo da última década, divulgou vários resultados de aferições realizadas com alunos brasileiros. Nos dois primeiros ciclos, participaram alunos das $1^{a}, 3^{a}$, $7^{\mathrm{a}}$ e $8^{\mathrm{a}}$ séries de escolas da rede pública de ensino. Do $3^{\circ}$ ciclo em diante, os alunos participantes foram da $4^{a}$ e $8^{a}$ séries do ensino fundamental e da $3^{a}$ série do ensino médio. Desde 1990 até o presente momento foram realizados seis ciclos de avaliação, $1^{\circ}$ Ciclo - 1990/91; $2^{\circ}$ Ciclo - 1993/94; $3^{\circ}$ Ciclo 1995/96; $4^{\circ}$ Ciclo - 1997/98; $5^{\circ}$ Ciclo - 2001/02; $6^{\circ}$ Ciclo - 2002/03; e $7^{\circ}$ Ciclo - 2005/06.

Estas avaliações do Saeb têm diferentes objetivos, como afirmam Ortigão e Sztajn (apud FRANCO, 2001).

\section{Quadro 1 - Objetivos Gerais do Saeb.}

\begin{tabular}{|c|c|}
\hline $\begin{array}{c}\text { Ciclo/ } \\
\text { ano }\end{array}$ & Objetivos Gerais \\
\hline 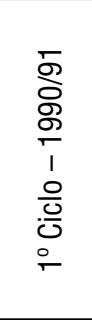 & $\begin{array}{l}\text { Desenvolver e aprofundar a capacidade avaliativa } \\
\text { das unidades geradoras do sistema educacional } \\
\text { MEC, Secretarias Estaduais e Órgãos Municipais) } \\
\text { regionalizar a operacionalização do processo } \\
\text { avaliativo criando nexos e estímulos para o } \\
\text { desenvolvimento de infra-estrutura de pesquisa e } \\
\text { avaliação educacional; propor uma estratégia de } \\
\text { articulação dos resultados das pesquisas eavaliações } \\
\text { já realizadas ou em vias de implementação. }\end{array}$ \\
\hline 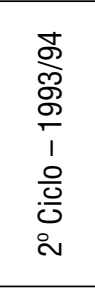 & $\begin{array}{l}\text { Fornecer elementos para apoiar a reformulação e } 0 \\
\text { monitoramento de políticas voltadas paraa melhoria da } \\
\text { qualidade da educação; promover o desenvolvimento } \\
\text { e o aperfeiçoamento institucional, organizacional e } \\
\text { operacional do Sistema Nacional de Avaliação da } \\
\text { Educação Básica - Saeb; incrementar, descentralizar } \\
\text { e desconcentrar a capacidade técnico-metodológica } \\
\text { na área de avaliação educacional no Brasil. }\end{array}$ \\
\hline 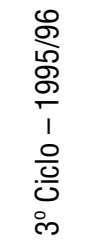 & $\begin{array}{l}\text { Fornecer subsídios para as políticas voltadas à } \\
\text { melhoria da qualidade, eqüidade e eficiência da } \\
\text { educação no Brasil. }\end{array}$ \\
\hline 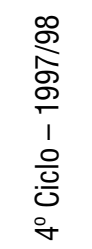 & $\begin{array}{l}\text { Gerar e organizar informações sobre a qualidade, } \\
\text { eqüidade e eficiência da educação nacional, de } \\
\text { forma a permitir o monitoramento das políticas } \\
\text { brasileiras. }\end{array}$ \\
\hline
\end{tabular}

Fonte: BONAMINO; FRANCO (1999, p. 15).

Tendo em vista estes objetivos Ravela (2002, p. 5) enfatiza:

[...] por sua própria natureza, a educação é uma atividade "opaca" quanto a seus resultados, em comparação com outras atividades humanas onde a sociedade tem mais facilidade em "ver" os resultados do que se faz. 0 fato das crianças estarem ou não aprendendo o que se espera não pode ser percebido diretamente, nem pela sociedade, nem pelas famílias.

A avaliação do rendimento dos sistemas educativos tem sido um dos objetivos das políticas públicas no Brasil, mas estes não estão devidamente priorizados ou contemplados de modo a promover mudanças estruturais na educação. Ao longo desta década presenciouse, no Brasil, o uso de provas normalizadas e/ou estandardizadas nestas aferições, com a finalidade de ampliar uma cultura de avaliação, utilizandose de amostras representativas com critérios de avaliação específicos para a leitura dos resultados.

Fontanive (1997, p. 33) aponta para a popularização da avaliação em larga escala 
referindo que sua principal função "não é selecionar, aprovar ou reprovar os alunos, mas sim identificar os níveis de aprendizagem de uma população ou subpopulação".

Como esclarece Ransan (2007), o termo avaliar provém do latim a-avalere que quer dizer "dar valor a". Ou seja, "atribuir valor ou qualidade a alguma coisa" que implica em um posicionamento positivo ou negativo com relação ao objeto.

De acordo com Depresbiteris (2001):

Avaliar um sistema educativo repousa na idéia de que uma escola é muito mais do que uma simples junção de classes. A escola existe em um certo contexto e é fundamental que este seja analisado, uma vez que se constitui em fator determinante para a qualidade de ensino (DEPRESBITERIS, 2001, p.140).

Apesar da complexidade da avaliação também podemos entender como este processo se faz necessário, pois, assim como discute Depresbiteris (2001):

...eles foram criados para estimular a assunção de responsabilidades e a visibilidade que devem ter os sistemas educativos na informação dos diversos atores, em nível individual, institucional, governamental e no conjunto da sociedade (DEPRESBITERIS, 2001, p.138).

Há uma necessidade de que cada escola continue realizando as suas avaliações no âmbito do micro, porém, para que estas instituições possam se posicionar em relação aos seus resultados no macro sistema torna-se necessário que realizem avaliações de sistemas. A partir destes resultados, estas avaliações atuarão como orientadoras das ações educativas e seus resultados serão utilizados como levantamento de hipóteses sobre possíveis causas de problemas encontrados nas escolas. E não como formas de punição dos estabelecimentos e elementos humanos (DEPRESBITERIS, 2001, p. 145, 146).

Como indica Santos (1995) se após a avaliação for detectado que os alunos não aprenderam determinados conteúdos, professores deverão trabalhar tal conteúdo, porém sem fazer dos resultados das avaliações de sistema uma referência para a construção curricular novamente.

Freitas (2004) critica o uso dos resultados por alguns governos, declara que as avaliações de larga escala podem servir para que o governo aumente o seu controle sobre as escolas, gerar competitividade entre as escolas e os Estados, ou que apesar do custo elevado na aplicação das mesmas, elas não são eficazmente utilizadas para lerem a realidade educacional brasileira.

O Saeb elabora matrizes por área do conhecimento que procuram mostrar o que tem sido realmente ensinado nas escolas brasileiras, Bonamino e Franco, (2001). Assim como diz Buriasco e Soares (2008):

Os resultados dos levantamentos do Saeb confirmam os problemas de desempenho escolar do sistema, apontam caminhos que permitem avaliar as políticas educacionais em curso no país e indicam áreas que devem ser consideradas nos investimentos para a melhoria da qualidade do ensino.

É desta forma que o governo poderá nortear os seus investimentos, analisando quais áreas que necessitam de mais de recursos.

Segundo Locatelli (2002) o Saeb tem objetivos amplos para a educação básica, tais como:

(i) monitorar a qualidade, a eqüidade e a efetividade do sistemadeeducação básica; (ii) ofereceràsadministrações públicas de educação, informações que Ihes permitam avaliar seus projetos educacionais e formular programas de melhoria da qualidade de ensino; e (iii) proporcionar aos agentes educacionais e à sociedade informes sobre os resultados dos processos de ensino e dos fatores contextuais a eles associados (LOCATELLI, 2002, p. 9).

Para que estas avaliações pudessem refletir a realidade de conteúdo trabalhado nas escolas, a seleção dos conteúdos foi realizada com base nos conteúdos mínimos comuns às propostas curriculares estaduais. Porém, assim como esclarece Buriasco e Soares (2008) nem sempre estes testes acontecem com tanta eficiência. Como o Brasil é formado por diversas regiões que se diferem entre si, nem sempre fica tão simples escolher os conteúdos comuns às propostas curriculares estaduais.

Conforme Buriasco e Soares (2008):

(...) essas avaliações (...) representam um problema, quando abrangem regiões com grande amplitude de variação nas suas condições sociais, econômicas e culturais, face à ocorrência de possíveis comparações destituídas de sentido e a generalizações comprometidas, tendo em vista as diversidades apontadas que deveriam ser levadas em consideração (...) (Buriasco, Soares, 2008, p.18). 
Com relação às políticas públicas de avaliação houve mudanças de estrutura nas avaliações de sistema. Como ações de políticas públicas de educação do governo Lula (2003 - 2006/2007 2011) foi instaurada a Prova Brasil em 2005 com o objetivo de medir o Índice de Desenvolvimento da Educação Básica (IDEB).

Pela primeira vez, no ano de 2005 a Prova Brasil foi aplicada em todo o país com o auxilio das secretarias municipais e estaduais. Tal prova foi idealizada para fornecer informações sobre o ensino oferecido pelos municípios e por cada escola. Teve como objetivo, auxiliar os governantes nas decisões do direcionamento de recursos técnicos e financeiros. Alunos de $4^{a}$ e $8^{a}$ séries realizaram as provas de Língua Portuguesa e Matemática.

Segundo Andrade; Melo; Silva (2007) afirmam que a Prova Brasil obtém médias de desempenho de alunos matriculados no Ensino Fundamental, com o auxilio do Saeb. Já o fluxo escolar é obtido através do Censo Escolar da Educação Básica. Através destes dois fatores (fluxo e aprendizagem), é que se expressam em números de 0 a 10 do IDEB.

Porém, alguns autores esclarecem alguns aspectos que podem criar um viés de resultados nas avaliações de larga escala.

Segundo Freitas (2004):

(...) ocampodesarticulou-seevoltou-separametodologias de ensino específicas e suas formas estritas de ensinar para atender a parâmetros curriculares. Os sistemas de ensino viram-se às voltas com uma verdadeira avalanche de processos externos de avaliação e credenciamento. A filosofia do controle como arma para gerar competência e qualidade tomou conta da maioria das políticas publicas conduzidas (FREITAS, 2004, p.148).

Ressalta que a avaliação tem sido realizada com o caráter de controle dos governos sobre as escolas, já Franco (2001), nos dá a sua contribuição tecendo outra crítica às avaliações em geral.

Ainda não conseguimos, entretanto, desenvolver um conjunto de recursos avaliativos correspondentes a essa percepção do papel da escola (o da transformação social), pois continuamos ainda presos a soluções orientadas muito mais na direção do acerto técnico do que do sociológico. Isto é, cuidamos, em geral, de elaborar boas provas e testes bem-feitos e atentamos pouco para os efeitos do uso desses instrumentos sobre 0 destino dos alunos (FRANCO, 2001, p. 30).
Assim sendo, as avaliações de larga escala têm sido amplamente utilizadas, porém é necessário que se faça uma análise crítica do processo, tanto na construção como nos resultados. Estas avaliações são articuladas por meio do plano de desenvolvimento da educação, como descritos abaixo.

\section{Plano de desenvolvimento da educação: avaliações de sistema no Brasil}

O plano de desenvolvimento da educação (PDE) visa uma educação básica de qualidade, pois investindo neste nível a educação profissional e superior são beneficiadas. Tal plano busca o sucesso e a permanência dos alunos incluindo a participação dos pais, alunos e profissionais da educação.

Uma medida importante do plano é avaliar o desempenho das crianças, com o intuito de verificar a qualidade do processo; incluindo metas para uma melhoria na educação básica.

\section{Índice de Desenvolvimento da Educação Básica}

Foi criado pelo INEP em 2007, o Índice de Desenvolvimento da Educação Básica (IDEB), com o intuito de garantir a qualidade da educação, analisando o fluxo escolar e medidas de desempenho nas avaliações.

A partir dos resultados deste índice são traçadas metas de qualidade para o sistema educacional. É por meio do Censo Escolar, Saeb e Prova Brasil que é calculado o IDEB. O Censo Escolar constitui-se a partir de dados das instituições públicas e privadas de ensino. Os dados coletados referem-se à formação de políticas públicas e também distribuição de recursos, como merenda, bibliotecas, distribuição de livros, transporte escolar e etc.

Os dados são coletados por meio do Educacenso, que se referem a informações das escolas, turmas, professores e alunos. O censo é responsável pelo diagnóstico da educação básica no Brasil, pois é por meio dele que as políticas públicas são pensadas e elaboradas. Por isso, a importância das escolas responderem o questionário. É a partir dos dados que o Ministério 
da Educação repassa recursos financeiros para a compra de matérias e para o Fundeb.

\section{Sistema de Avaliação da Educação Básica}

O Saeb surgiu no final dos anos 80 , foi a $1^{\text {a }}$ iniciativa nacional para conhecer melhor o sistema educacional brasileiro. Em 1995 o Saeb passou a comparar dados de diversos anos e é por meio destes dados que pode-se fazer um diagnóstico da educação, verificando a qualidade e o desempenho do ensino brasileiro.

OSistema de Avaliação da Educação Básica(Saeb) coleta informações sobre o desempenho acadêmico dos alunos brasileiros, apontando o que sabem e são capazes de fazer, em diversos momentos de seu percurso escolar, considerando as condições existentes nas escolas. Os dados, obtidos com a aplicação de provas aos alunos e de questionários a alunos, professores e diretores, permitem acompanhar a evolução do desempenho de diversos fatores associados à qualidade e à efetividade do ensino ministrado nas escolas. (MINISTÉRIO DA EDUCAÇÃO/ SAEB, 2005, p.3)

O Saeb ocorre a cada dois anos para avaliar alunos de $4^{\circ}$ e $8^{\circ}$ série do ensino fundamental (Prova Brasil) e $3^{\circ}$ ano do ensino médio (Enem). São avaliadas escolas públicas e particulares, com provas de língua portuguesa (foco na leitura) e matemática (foco em resoluções de problemas).

O Saeb aplica questionários contextuais aos professores, diretores, escola e aluno.

Esses instrumentos têm como objetivo levantar informações a origem familiar dos alunos, seus hábitos e condições de estudo, bem como os estilos pedagógicos de seus professore e a forma de gestão das escolas (FRANCO, 2001, p. 17).

Essa avaliação é amostral; "que testa amostras probabilísticas complexas das diversas unidades da federação (estados e o distrito federal)." (FRANCO, 2001, p. 16) e oferece resultados apenas no ensino brasileiro.

As provas são aplicadas por profissionais terceirizados, treinados para manter o padrão dos testes. Tais profissionais agendam com as escolas a data e horário da prova a ser aplicada. Ao término da prova os alunos respondem a um questionário socioeconômico e cultural com 44 questões.

Após as médias de desempenho nas avaliações serem calculadas elas são utilizadas para o cálculo do IDEB, nota-se, portanto, que essa avaliação é imprescindível como ação concreta para se alcançar as metas do PDE.

\section{Prova Brasil}

A Prova Brasil foi criada no ano de 2005, visando tornar a avaliação mais detalhada. A Prova Brasil é um complemento do Saeb, ela é censitária (expande o alcance dos resultados), oferecendo resultados não só a União, mas também a municípios e escolas participantes.

Esse programa avalia alunos da rede pública urbana de $4^{\circ}$ e $8^{\circ}$ série do ensino fundamental e operacionalizada em conjunto com o Saeb, pois possui a mesma metodologia.

A prova avalia língua portuguesa e a matemática por meio de testes padronizados e aplica-se um questionário socioeconômico. Os professores e diretores também são avaliados através de questionários que fornecem dados importantes sobre a educação.

A Prova Brasil bem como o Saeb tem participação voluntária. Enquanto o Saeb faz sorteios das escolas que irão participar, na Prova Brasil a escolha é feita pelas secretarias estaduais e municipais de educação.

A prova é organizada em 21 tipos diferentes de caderno de prova para cada série, em que cada aluno responde a um caderno, cada caderno de prova é composto por quatro blocos, em que dois são de português e dois são de matemática; os testes são de múltipla escolha com quatro ou cinco alternativas de resposta para cada questão, mas apenas uma está correta.

A partir da nota da Prova Brasil os professores, diretos e gestores poderão promover debates pedagógicos, visando discutir a qualidade da educação por meio dos resultados e seus próprios objetivos.

Ao analisar o programa do governo Lula, relacionando-o à legislação percebe-se que com a democratização do acesso ao ensino fundamental, houve diminuição da qualidade das escolas públicas, os recursos destinados à educação em sua maioria são vinculados a garantia ao acesso do ensino obrigatório. 


\section{Discussões e Considerações Finais}

A Tabela 1 indica os primeiros resultados das médias de desempenho do Saeb1995/2005 em que se trabalha com os dados do Brasil e Paraná.

Tabela 1- Saeb1995/2005. Médias comparadas do desempenho em Matemática

\begin{tabular}{|c|c|c|c|c|c|c|}
\hline \multicolumn{7}{|c|}{ Médias de Proficiência em Matemática-Brasil 4ª série } \\
\hline ANO & 1995 & 1997 & 1999 & 2001 & 2003 & 2005 \\
\hline & 190,6 & 190,8 & 181 & 176,3 & 177,1 & 182 \\
\hline \multicolumn{7}{|c|}{ Médias de Proficiência em Matemática - $4^{\mathrm{a}}$ série E.F. Escolas Urbanas sem Federais } \\
\hline \multirow[t]{2}{*}{ ANO } & 1995 & 1997 & 1999 & 2001 & 2003 & 2005 \\
\hline & 198,9 & 200 & 187,1 & 187,3 & 183,6 & 203 \\
\hline \multicolumn{7}{|c|}{ Médias de Proficiência em Matemática - 4ª série E.F. Escolas Urbanas Estaduais } \\
\hline \multirow[t]{2}{*}{ ANO } & 1995 & 1997 & 1999 & 2001 & 2003 & 2005 \\
\hline & 193,5 & 215,5 & 190,4 & 194,8 & 201 & 208,3 \\
\hline \multicolumn{7}{|c|}{ Médias de Proficiência em Matemática - $4^{a}$ série E.F. Escolas Urbanas Municipais } \\
\hline \multirow[t]{2}{*}{ ANO } & 1995 & 1997 & 1999 & 2001 & 2003 & 2005 \\
\hline & 193 & 189,2 & 180,9 & 180,8 & 176,9 & 198,8 \\
\hline \multicolumn{7}{|c|}{ Médias de Proficiência em Matemática - 4ª série E.F. Escolas Urbanas Particulares } \\
\hline \multirow[t]{2}{*}{ ANO } & 1995 & 1997 & 1999 & 2001 & 2003 & 2005 \\
\hline & 242,7 & 245,1 & 236,8 & 235,1 & 235,5 & 239 \\
\hline \multicolumn{7}{|c|}{ Médias de Proficiência em Matemática - $4^{\mathrm{a}}$ série E.F. Escolas Federais } \\
\hline \multirow[t]{2}{*}{ ANO } & 1995 & 1997 & 1999 & 2001 & 2003 & 2005 \\
\hline & - & - & - & - & 233 & 244 \\
\hline \multicolumn{7}{|c|}{ Médias de Proficiência em Matemática - $4^{a}$ série E.F. Escolas Urbanas sem Federais } \\
\hline & & & & Total & Capital & Interior \\
\hline BRASIL & & & & 185,7 & 190,2 & 184,2 \\
\hline PARANÁ & & & & 202,9 & 203,4 & 202,8 \\
\hline \multicolumn{7}{|c|}{ Cont.Tabela 1-Saeb 1995/2005. Médias comparadas do desempenho em Matemática. } \\
\hline \multicolumn{7}{|c|}{ Médias de Proficiência em Matemática - Escolas Urbanas Estaduais e Municipais } \\
\hline & & & & Total & Capital & Interior \\
\hline BRASIL & & & & 180,1 & 180,9 & 179,8 \\
\hline PARANÁ & & & & 199,4 & 194,4 & 200,3 \\
\hline \multicolumn{7}{|c|}{ Médias de Proficiência em Matemática - 4ª série E.F.Urbanas Estaduais } \\
\hline & & & & Total & Capital & Interior \\
\hline BRASIL & & & & 181,8 & 183,7 & 181,2 \\
\hline PARANÁ & & & & 208,3 & 208,5 & 208,2 \\
\hline \multicolumn{7}{|c|}{ Médias de Proficiência em Matemática - 4ª série E.F. Escolas Urbanas Municipais 2005} \\
\hline & & & & Total & Capital & Interior \\
\hline BRASIL & & & & 178,9 & 178,8 & 179 \\
\hline PARANÁ & & & & 198,8 & 190,6 & 199,9 \\
\hline \multicolumn{7}{|c|}{ Médias de Proficiência em Matemática - 4ª série E.F. Escolas Particulares 2005} \\
\hline & & & & Total & Capital & Interior \\
\hline BRASIL & & & & 226,4 & 228,5 & 225 \\
\hline PARANÁ & & & & 239,1 & 248,3 & 235,1 \\
\hline
\end{tabular}

Fonte: Dados retirados de< http://www.inep.gov.br/>. Acesso em maio 2009 e modificado pela autora. 
As médias da proficiência em Matemática/ $4^{a}$ série/ 1995/2005 apresenta dados em que no Brasil houve um decréscimo nas médias de proficiência. Com relação às escolas urbanas, sem as escolas federais, urbanas estaduais e urbanas municipais, houve um aumento nas médias de proficiência podendo indicar que um trabalho de política pública voltado para os elementos locais podem incidir num trabalho mais efetivo e coerente realizado pelos órgãos municipais.

Com relação às médias da proficiência em Matemática/ $4^{a}$ série/ 1995/2005 comparando Brasil e Paraná tem-se um acréscimo de proficiência no Paraná com relação às comparações entre Escolas da Capital e do interior. A diferença entre cidades do Paraná da capital e do interior não tem uma diferença tão relevante, este estudo será ponto relevante a partir da continuação deste projeto.

Os resultados do Saeb e desta pesquisa devem ser trabalhados num processo de disseminação de informações, o mais direto possível com os atores sociais envolvidos, com sentido ético e político na promoção do ser humano. Indicando e discutindo pontos que precisam ser revistos e analisados pelos professores e pesquisadores da área em questão.

Estas dimensões começam a responder ao aprofundamento da análise já trilhada em outras pesquisas e iniciadas neste primeiro momento desta pesquisa. A continuidade, entretanto implica construção de novas reflexões acerca do elemento central do projeto de pesquisa apresentado para o Observatório, qual seja, a relação entre investimento, condições de qualidade e resultados escolares.

Os resultados do Saeb e a análise da oferta e do financiamento parecem indicar de modo muito genérico a expansão da oferta de educação infantil; a municipalização desta oferta; certa estabilização da oferta de ensino fundamental; tal movimentação sendo efetivada em condições desiguais de financiamento no âmbito das regiões. Frente a isto parece que a pergunta a ser respondida é: as condições desiguais de financiamento da educação se traduzem em condições desiguais de oferta e de resultados escolares (proficiência no Saeb)?

Para avançar em análises que nos permitam construir respostas a esta questão temos como tarefas:
- Caracterização das condições de oferta na região que ultrapassem a matrícula, a partir da análise dos demais dados do censo sobre as escolas (perfil dos estabelecimentos) e dos dados do Saeb;

- Caracterização dos resultados escolares na região: aprovação; reprovação; abandono; proficiência;

- Construção de um índice de condições de oferta e utilização do IDEB.

Após a análise dos dados do Saeb no âmbito do Estado do Paraná, a pesquisa será nas regiões metropolitanas (Curitiba e Londrina) onde alguns municípios serão selecionados para estudos de caso. Os estudos de caso serão realizados após o mapeamento das condições gerais do estado no cotejamento dos extremos (condições de financiamento e resultados) mediados pelos dados de condições de qualidade. Com relação aos recursos destinados à educação, as desigualdades regionais explicitadas incidem na composição desse investimento, apresentando crescimento constante e desigual.

No caso paranaense o regime de colaboração implica divisão de responsabilidade entre estados e municípios em que o primeiro atende as séries finais e o segundo as séries iniciais do ensino fundamental. Assim pensar a concretização do direito à educação num espaço determinado não pode prescindir da análise do encontro das ações dos diferentes entes da federação na implementação da política educacional.

O estudo realizado permitiu conhecer os resultados do Saeb no Paraná, identificar e mapear, ainda que não totalmente, os vários determinantes da qualidade do ensino no Paraná. A busca por uma compreensão aguçada de tais determinantes e a preocupação em relacioná-los com os conceitos subjacentes esteve sempre presente nesta pesquisa.

Avaliações em larga escala podem proporcionar espaços de discussão sobre conteúdos relevantes e pertinentes no atual momento histórico, político e cultural do país. Políticas públicas podem buscar novas formas de avaliação propondo testes formais e informais, que contemplem habilidades básicas e tarefas mais complexas e avaliem a aplicação e 
compreensão de conhecimentos, além de testes informais que caracterizem o fazer didático presente no cotidiano.

$\mathrm{Na}$ educação assim como na vida em geral, os fatos acontecem de uma maneira dinâmica. Com isso fica difícil isolar as variáveis envolvidas, correndo-se o risco de submeter à complexa realidade dos fenômenos educacionais a um esquema simplificado de análise. À medida que avançam os estudos educacionais, mais evidentes se tornam seu caráter de fluidez dinâmica, de mudança do processo educativo, propício para o estabelecimento de uma continuidade no ensino.

Com isso a Educação torna-se um elemento capaz de estabelecer contato com a realidade, podendo indicar caminhos de mudanças que proporcionem às pessoas um desenvolvimento capaz de interferir em situações novas e tomar decisões que viabilizem uma sociedade menos desigual. Alguns princípios ou proposições precisamserdiscutidos, efazerpartedasavaliações de rendimento: transparência, consistência e diversidade. No que se refere à transparência, o acesso às informações e a linguagem utilizada para compor os testes e comunicar os resultados das avaliações; no que se refere à consistência, a validação dos testes e as habilidades avaliadas; no que se referem à diversidade, os instrumentos utilizados levando-se em consideração valores culturais e sociais dos alunos.

\section{Referências Bibliográficas}

ANDRADE, M.; MELO, R. L. C.; SILVA, S. E. Ided: aluno aprovado e sabendo o conteúdo. Dimensão Pedagógica, v. 13, n. 77, set./out. 2007.

BISHOP, A. J. Mathematical Enculturation: a cultural perspective on mathematics education. Reidel, Dordrecht: Kluwer Academic, 1988.

BONAMINO, A. C. de ; FRANCO, C. Avaliação e política educacional: o processo de institucionalização do SAEB. Cadernos de Pesquisa, São Paulo, n. 108, p. 101-132, nov. 1999.

BONAMINO, A.; FRANCO, C. Iniciativas Recentes de Avaliação da Qualidade da Educação no Brasil. In FRANCO, C. (org) Avaliação, ciclos e promoção na educação. Porto Alegre: Artmed, 2001.

BURGHES, D.; KAUR, B.; Thompson, D. R., (Ed.). International Project on Mathematical Attainment: report. Budapeste: WoltersKluwer, 2004. (Series of International Monograhs on Mathematics Teaching Worldwide, Monograph, 4). $292 \mathrm{p}$.

BURIASCO, L. C.; SOARES, M. T. C. S. Avaliação de sistemas escolares: da classificação dos alunos à perspectiva de análise de sua produção matemática. In VALENTE, W. R. Avaliação Matemática: história e perspectivas atuais. Campinas: Papirus, 2008.

DEPRESBITERIS, L. A avaliação na educação básica: ampliando a discussão. In: . Estudos em Avaliação Educacional. Fundação Carlos Chagas, n. 24 jul./dez. 2001.

D' AMBROSIO, U. Cultural Framing of Mathematics Teaching and Learning. In: BIEHLER, R. et al. (Eds.). Didactics of Mathematics as a Scientific Discipline. Dordrecht: Kluwer Academic, 1994.

FONTANIVE, N. S. Avaliação em larga escala e padrões curriculares: as escalas de proficiência em matemática e leitura no Brasil. In: BOMENY, H. (Org.) Avaliação e determinação de padrões na educação latino-americana: realidades e desafios. Rio de Janeiro: FGV, 1997. p.31-46.

FRANCO, C. (Org.). Avaliação, Ciclos e Promoção na Educação. Porto Alegre: ArtMed , 2001.

FREITAS, L. C. Ciclos, seriação e avaliação: confronto de lógicas. São Paulo: Moderna, 2003. (Coleção Cotidiano Escolar).

. Crítica da Organização do Trabalho Pedagógico e da Didática. Campinas, SP: Papirus, 1995. (Coleção Magistério: Formação e Trabalho Pedagógico).

A Avaliação e as reformas dos anos de 1990: novas formas de exclusão, velhas formas de subordinação. In: Educação \& Sociedade, v. 25. São Paulo: Cortez; Campinas, 2004.

LOCATELLI, I. Construção de instrumentos para avaliação de larga escala e inicadores de rendimento: o modelo SAEB. In: Estudos em Avaliação Educacional. Fundação Carlos Chagas, n. 25, jan./jun. 2002. 
MORA, D. Didáctica de las matemáticas. Caracas: Ediciones de la Universidad Central de Venezuela, 2002.

ORGANIZACIÓN PARA LA COOPERACIÓN Y EL DESARROLLO ECONÓMICOS. Knowledge and skills for life: first results from the OCDE. Programm for International Student Assessment (PISA). Paris, 2000.

POLI, E. C.; BATISTA, D. A. Avaliação em larga escala: um estudo longitudinal em educação matemática. In: SIMPÓSIO DE PESQUISA E PÓS-GRADUAÇÃO EM EDUCAÇÃO DOS PROGRAMAS DA IES PÚBLICAS DO PARANÁ, 1., 2001. Anais... Londrina: Universidade Estadual de Londrina, 2001. p. 119-130.

POLI, E. C. Kassel Projects in Brazil. In: BURGHES, D.; KAUR, B.; Thompson, D. R. (Eds.). Kassel Project: final report. Budapeste: WoltersKluwer Co., 2004a. p. 41- 44. (Series of International Monograhs on Mathematics Teaching Worldwide, Monograph, 3).

International Project on Mathematical Attainment: Brazil. In: BURGHES, D.; KAUR, B.; Thompson, D. R. (Eds.). International Project on Mathematical Attainment: report. Budapeste: WoltersKluwer Co., 2004b. p. 27-36. (Series of International Monograhs on Mathematics Teaching Worldwide, Monograph, 4).

RANSAN, G. S. S. Avaliar para Promover. Disponível em: <http://www.sbs.com.br/virtual/etalk/index. asp?cod=1032>. Acesso em: 30 jul. 2007.

RAVELA, P. Introdução. In: WOLFE, R.; VALVERDE, G.; ESQUIVEL, J. M. Os próximos passos: como avançar na avaliação de aprendizagens na América Latina? São Paulo: Fundação Getulio Vargas/Centro de Pesquisa e Documentação de História Contemporânea do Brasil, 2002. p. 5-1. (Série PREAL Documentos, n.20).

SANTOS, S. M. Algumas considerações sobre avaliação e o estudo do erro. 1995. Monografia (Curso de Especialização em Educação Matemática) - Universidade Estadual de Londrina, Londrina, 1995.

http://www.inep.gov.br/internacional/pisa/. Acesso em: 25 nov. 2008

http://search.live.com/results.aspx?mkt=pt-br\&FORM=TOOLBR\&q=pisa-2006+brasil\&FORM=TOOLBR . Acesso em: 25 nov. 2008

http://www.inep.gov.br/basica/censo/ Acesso em: 25 nov. 2008

http://portal.mec.gov.br/index.php?option=com_content\&task=view\&id=8368 Acesso em: 25 nov. 2008

MINISTÉRIO DA EDUCAÇÃO- Instituto Nacional de estudos e pesquisas educacionais Anísio Teixeira/ SAEB2005. Primeiros Resultados: Médias de desempenho do SAEB/2005 em perspectiva comparada. Fev. 2007. 